\title{
Intestinal malignancy masquerading as primary ovarian carcinoma
}

\author{
Mona Asnani*, Kumkum Srivastava, Lubna Inam, Shipra Kunwar, Shivani Singh
}

Department of Obstetrics \& Gynaecology, Era's Lucknow Medical College, Lucknow, Uttar Pradesh, India

Received: 03 March 2015

Accepted: 19 April 2015

\section{*Correspondence:}

Dr. Mona Asnani,

E-mail: drdkbajaj@ rocketmail.com

Copyright: () the author(s), publisher and licensee Medip Academy. This is an open-access article distributed under the terms of the Creative Commons Attribution Non-Commercial License, which permits unrestricted non-commercial use, distribution, and reproduction in any medium, provided the original work is properly cited.

\begin{abstract}
About 4-5\% of ovarian tumours are metastatic from other organs, most frequently from the female genital tract, the breast, or the gastrointestinal tract. Ovarian metastases constitute $76 \%$ of genital tract metastases from extragenital primary tumours, of which $78 \%$ arise in the gastrointestinal tract. Metastatic ovarian tumours, often mistaken as primary ovarian carcinomas. A 37 year old P2+0 presented with c/o - Abdominal distension since last 6 months. It was associated with anorexia, constipation and generalised weakness. Not having any menstrual complaint. P/A: moderate ascitis was there. A mass of $8 \times 10 \mathrm{~cm}$ felt through right fornix extending up to right iliac fossa. Mass was firm in consistency with restricted mobility. Uterus felt separately from the mass. Left fornix clear. A right sided ovarian mass of approx. 10x15 cm of variegated consistency identified. Bladder wall was thickened. Small nodules of approximately $1 \mathrm{~cm}$ present over dome of bladder under visceral peritoneum. Omentum, ascending colon, transverse colon, descending colon, caecum, greater curvature and lesser curvature were thickened. Liver and spleen were normal. Total abdominal hysterectomy with bilateral Salpingo oophorectomy with partial omentectomy was done. Histopathology Revealed metastatic adenocarcinoma of the genital tract and B/L ovaries. So it was concluded that secondaries from intestinal malignancy can present as primary ovarian malignancy.
\end{abstract}

Keywords: Primary ovarian carcinoma, Intestinal malignancy, Metastases

\section{INTRODUCTION}

About 4-5 \% of ovarian tumours are metastatic from other organs, most frequently from the female genital tract, the breast, or the gastrointestinal tract. ${ }^{1}$ Ovarian metastases constitute $76 \%$ of genital tract metastases from extragenital primary tumours, of which $78 \%$ arise in the gastrointestinal tract. ${ }^{2}$ Metastatic ovarian tumours, often mistaken as Primary ovarian carcinomas.

\section{CASE REPORT}

A 37 year old $\mathrm{P} 2+0$ presented with c/o - Abdominal distension since last 6 months. It was associated with anorexia, constipation and generalised weakness. She was not having any menstrual complaint. On abdominal examination moderate ascitis was there. Omentum felt as firm to hard omental cake. A vague mass of approximately $8 \times 10 \mathrm{~cm}$ felt in the right iliac fossa extending to hypogastrium. Lower end of the mass not reachable. On per vaginal examination uterus parous size, anteverted. A mass of $8 \times 10 \mathrm{~cm}$ felt through right fornix extending up to right iliac fossa. Mass was firm in consistency with restricted mobility. Uterus felt separately from the mass. Left fornix clear. Her blood investigation revealed $\mathrm{Hb}=8.5 \mathrm{gm} \%$ and all other investigation (CBC, LFT, KFT, S. electrolytes, chest Xray PA view) were within normal limit. CA $125=14.7$ IU.

MRI and CECT abdomen - Moderate sized, well defined space occupying lesion, displaying mixed signal 
intensities s/o mixed solid \& cystic component, of approx. $11 \times 10 \mathrm{~cm}$ noted involving both adnexa in the pelvic region reaching up to umbilicus with omental caking, and thickened coecal wall - Findings are likely suggestive of Malignant ovarian tumour with Uterine fibroids. With the help of clinical examination and radiological investigation, a diagnosis of right sided ovarian tumour most likely malignant with uterine fibroids was made.

Patient prepared for laparotomy. One unit blood was transfused preoperatively and one unit in the postoperative period. 3.5-4 literes of haemorrhagic fluid was drained. A right sided ovarian mass of approx. 10x15 cm of variegated consistency identified. Bladder wall was thickened. Small nodules of approximately $1 \mathrm{~cm}$ present over dome of bladder under visceral peritoneum. Omentum, ascending colon, transverse colon, descending colon, caecum, greater curvature and lesser curvature were thickened. Liver and spleen were normal. Total abdominal hysterectomy with bilateral Salpingo oophorectomy with partial omentectomy was done. Tissues were sent for histopathology. Histopathology Revealed metastatic adenocarcinoma of the genital tract and $\mathrm{B} / \mathrm{L}$ ovaries. The enlarged right ovary revealed ovarian oedema. After HPE reporting a diagnosis of metastatic adenocarcinoma of most probably large intestine was made.

The patient was planned for further workup and chemotherapy but unfortunately she expired within 20 days of the surgery.

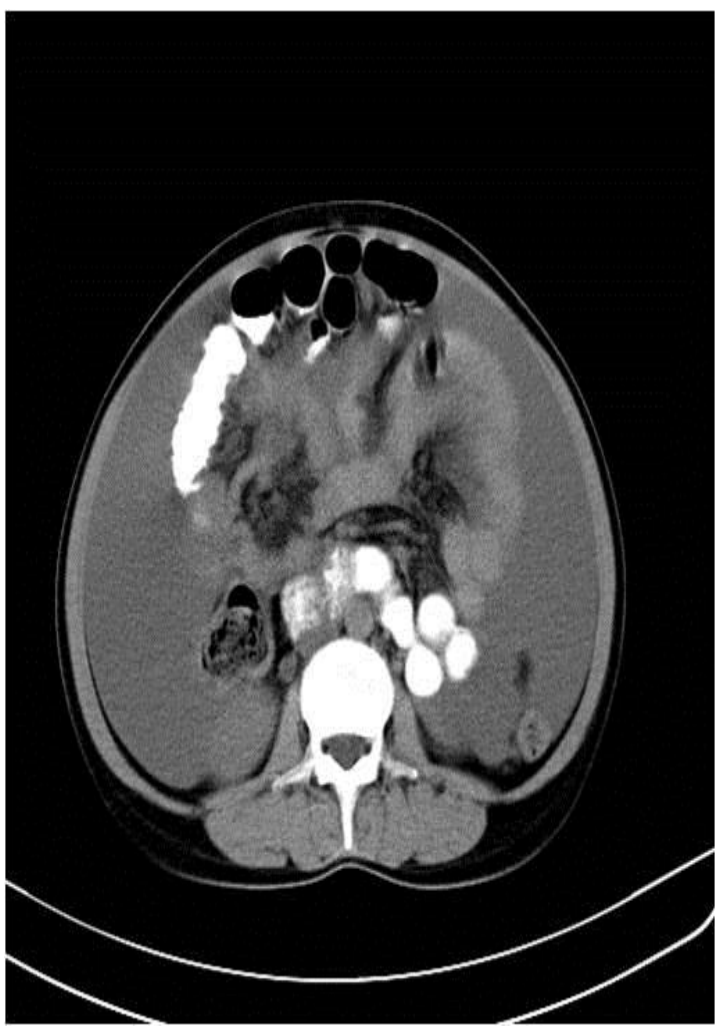

Figure 1: MRI showing caecal wall thickening.

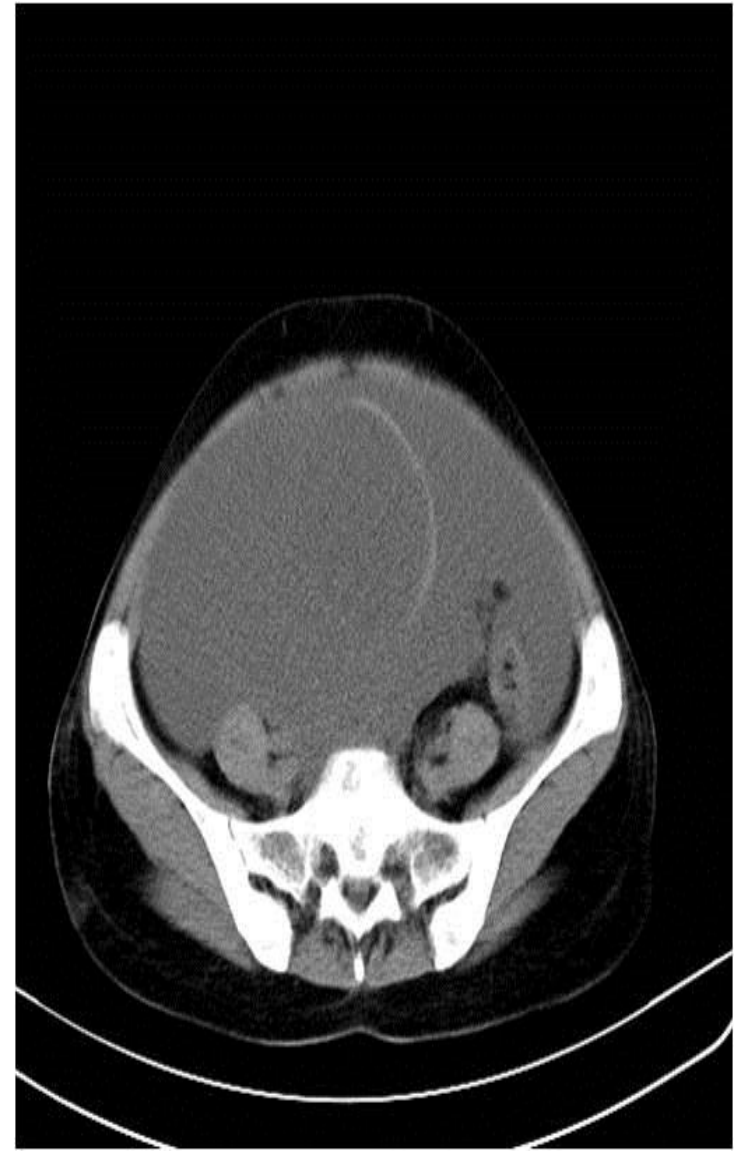

Figure 2: MRI showing adnexal mass.

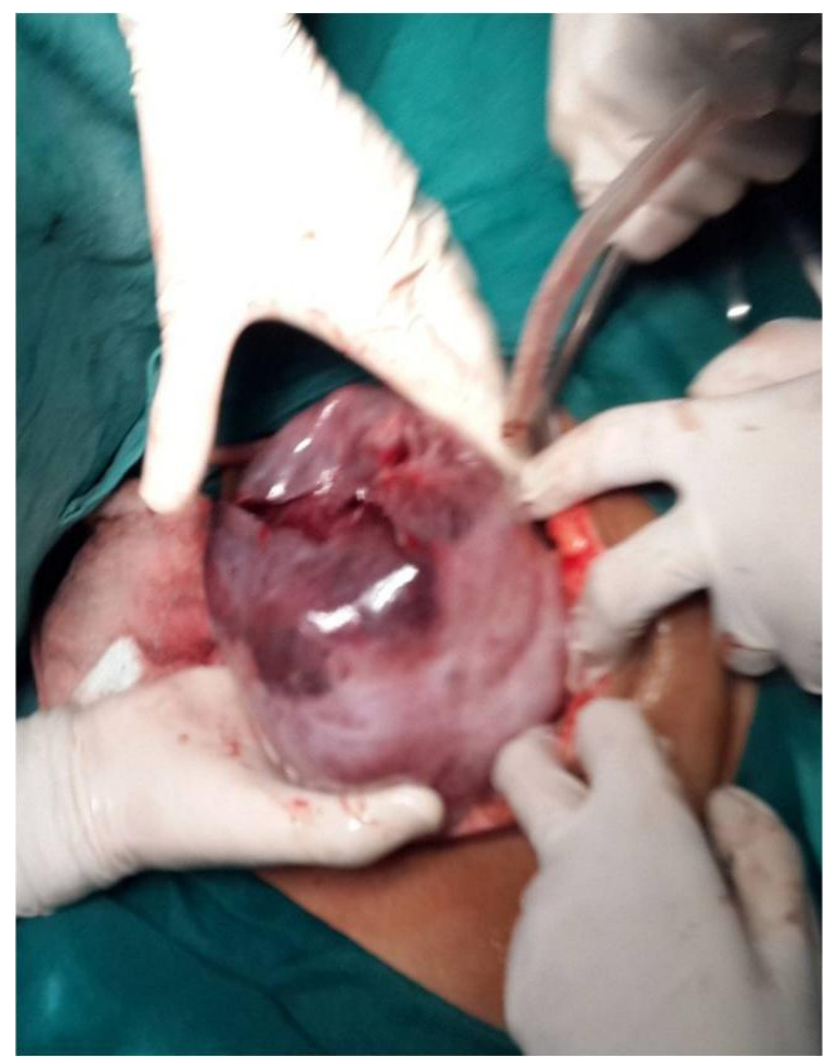

Figure 3: Right ovarian mass. 


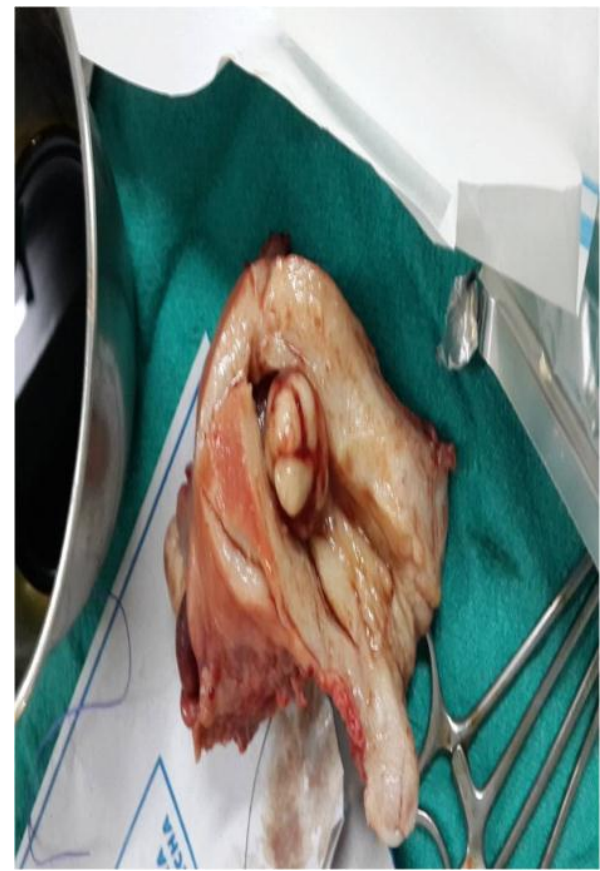

Figure 4: Intramural fibroid.

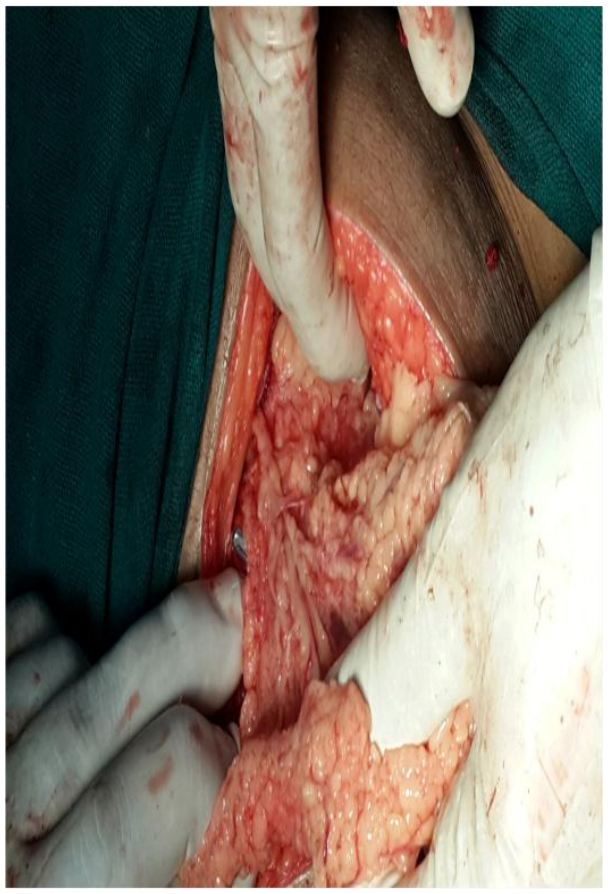

Figure 5: Omental thickening.

\section{DISCUSSION}

Intestinal malignancies, mainly from the rectum or sigmoid colon $(77 \%)$ spread to the ovary. ${ }^{1}$ Clinical presentation may be of intestinal carcinoma antedating ovarian tumour (50-75\% of cases) or of an ovarian tumour
(3-20\% of cases). ${ }^{3}$ The distinction of metastatic ovarian carcinoma from a primary malignant ovarian neoplasm is crucial to its subsequent management. ${ }^{4}$ In our case the patient presented as a case of primary ovarian malignancy. Up to $45 \%$ metastases from the large intestine are clinically interpreted as primary ovarian carcinomas, because of large size and predominantly cystic. On microscopic examination also they closely mimics primary ovarian adenocarcinoma.

In our case we get an unusual finding of diffuse massive oedema of right ovary. Massive ovarian oedema due to permeation of the ovarian lymphatics by metastatic carcinoma is rare, with a few cases reported to date. ${ }^{4}$ Few studies have addressed the more common problem of accurate diagnosis of metastatic colonic adenocarcinoma. ${ }^{5}$ A thorough history facilitates the diagnosis, but occasionally, a complete clinical history is not available or the ovarian tumour may be the first indication of an unsuspected primary carcinoma of the colon. Integration of clinicopathologic, immunohistochemical and cytogenetic features is helpful for the differential diagnosis of metastases of colorectal carcinomas from primary ovarian carcinomas. ${ }^{5}$ In case of an ovarian tumour, metastatic disease should always be considered to avoid pitfalls in diagnosis and therapy. The gastrointestinal tract is the most likely location of primary tumour, followed by breast and endometrium.

Funding: No funding sources

Conflict of interest: None declared

Ethical approval: Not required

\section{REFERENCES}

1. Young RH, Scully RE. Metastatic tumors in the ovary: a problem-oriented approach and review of the recent literature. Semin Diagn Pathol. 1991;8:250-76.

2. Demopoulos RI, Touger L, Dubin N. Secondary ovarian carcinoma: a clinical and pathological evaluation. Int J Gynecol Pathol. 1987;6:166-75.

3. Daya D, Nazeraly L, Frank GL. Metastatic ovarian carcinoma of large intestinal origin simulating primary ovarian carcinoma: a clinicopathologic study of 25 cases. Am J Clin Pathol. 1992;97:751-758.

4. Young RH, Scully RE. Metastatic tumors of the ovary. In: Kurman RJ, eds. Blaustein's Pathology of the Female Genital Tract. 4th ed. New York, NY: Springer-Verlag; 1994: 939-974.

5. Lash RH, Hart WR. Intestinal adenocarcinomas metastatic to the ovaries: a clinico-pathologic evaluation of 22 cases. Am J Surg Pathol. 1987;11:114-21.

DOI: $10.18203 / 2320-1770.1 j r \operatorname{cog} 20150107$

Cite this article as: Asnani M, Srivastava K, Inam L, Kunwar S, Shivani Singh. Intestinal malignancy masquerading as primary ovarian carcinoma. Int J Reprod Contracept Obstet Gynecol 2015;4:848-50. 